
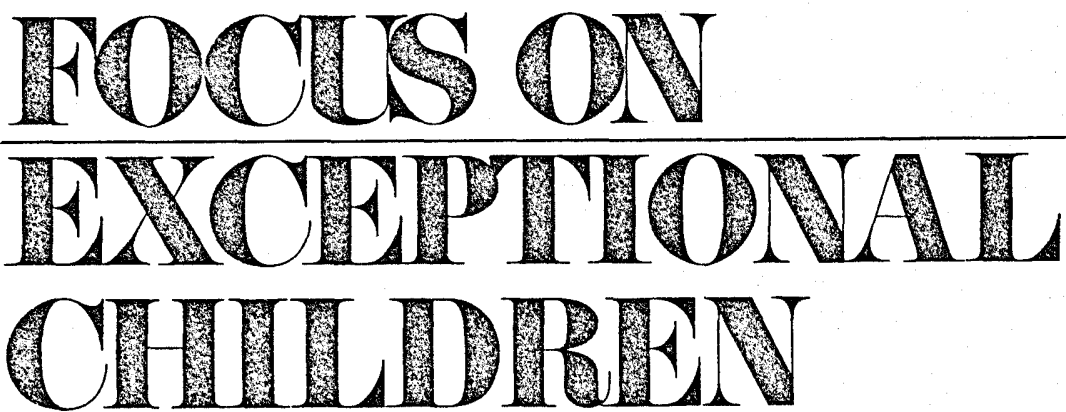

\title{
Parent Education Programs That Work: A Model
}

\author{
Roger Kroth and Harriet Otteni
}

Some people may see an inconsistency in the fact that a parent involvement center was conceived, developed, and is now flourishing in Albuquerque, New Mexico - a state that chose to not participate in the Education for All Handicapped Children Act, PL 94-142. Those who know the people and their values, however, realize that having a parent center whose main purpose is to further cooperative relationships and positive interactions between parents and school personnel is not incongruous at all. In fact, parents and professionals joined forces in a lawsuit against state officials in 1975 - to provide more services for exceptional children. Organizations such as the New Mexico Association for Retarded Citizens, the New Mexico Federation of the Council for Exceptional Children, the Albuquerque Association for Children with Learning Disabilities, and the Albuquerque Association for Gifted and Talented Students, as well as individual parents and professionals have worked together for many years to further the education of exceptional children. Thus, a Parent Center, housed in a wing of the Inez Elementary School, financially supported and staffed by the Albuquerque Public School (APS) system, with support from staff at the University of New Mexico (UNM), came into being.

Although the current focus of the Parent Center is on the parents and professionals of the APS population, the tentacles of the Center reach throughout the state and across the nation. Thousands of parents and school personnel from the other 49 states and a few foreign countries have visited the Center and have been trained by Center staff. Materials developed at the Center are currently being used in most states by university professors, principals, classroom teachers, and parents of exceptional children in rural and urban settings, with Native American, Hispanic and Black populations, and at a wide range of socioeconomic levels.

The Albuquerque Public Schools encompass a large, urban district of 75,150 students. The primary emphasis of the Parent Center is the special education population of approximately 11,000 children. Staffed by three coordinators of parent

Roger Kroth is a member of the Special Education staff at the University of New Mexico, and Harriet Otteni is coordinator for the Parent Involvement Center in the Albuquerque Public School System. 
involvement, the Center is founded on the philosophy that "parents must be recognized as special educators, the true experts on their children; and professional people have to learn to be consultants to parents" (Hobbs, 1978). Fundamental to the development of integrated services to assist parents and educators in achieving cooperative working relationships are the following beliefs:

- Education is a partnership between home and school.

- Parents, like children and teachers, are individuals who bring a variety of strengths and needs to this partnership.

- School personnel have a responsibility to utilize those strengths and meet those needs.

- Communication and cooperation between parents and teachers are accomplished through multiple approaches.

- Growth and development of children are enhanced when the significant adults in their lives interact effectively.

\section{SERVICES OF THE PARENT CENTER}

Recognizing that the home-school partnership is a shared responsibility, the Parent Center defines and outlines its services to the district within three categories.

FOCUS ON EXCEPTIONAL CHILDREN (ISSN 0015-511X) (USPS 203-360) is published monthly except June, July, and August as a service to teachers, special educators, curriculum specialists, administrators, and those concerned with the special education of exceptional children. This journal is abstracted and indexed in Exceptional Child Education Resources, and is also a vailable in microform from Xerox University Microfilms, Ann Arbor, Michigan. Subscription rates, $\$ 15.00$ per year. Copyright 1983, Love Publishing Company. All rights reserved. Reproduction in whole or part without written permission is prohibited. Printed in the United States of America. Second class postage is paid at Denver, Colorado. POSTMASTER: Send address changes to:

Love Publishing Company

Executive and Editorial Office

1777 South Bellaire Street

Denver, Colorado 80222

Telephone (303) 757-2579

\section{EDITORIAL BOARD}

Edward L. Meyen

University of Kansas
Glenn A. Vergason

Georgia State University

Richard J. Whelan

University of Kansas Medical Center

Carolyn Acheson

Senior Editor
Stanley F. Love Publisher
1. Services to schools.

a. Assisting school staffs in planning and implementing parent involvement at the classroom, building, or area level.

b. Conducting inservice training on the awareness, knowledge, and skills related to home-school communication.

c. Providing consultation and support services to school personnel as they work with parents.

d. Offering on-site graduate coursework in parent involvement through the University of New Mexico.

2. Services to parents.

a. Helping parents locate community resources.

b. Conducting parent workshops, seminars, and support groups.

c. Providing information and consultation related to individual parent needs.

d. Offering relocation service to parents of exceptional children who are moving to another locale.

3. Materials development.

a. Collecting and compiling information that facilitates better understanding and improved practices between school and home.

b. Acquiring and designing materials for use in parent and teacher workshops and seminars.

c. Providing information related to home-school needs through distribution of newsletters, handouts, and other media.

d. Maintaining a parent/professional use library that houses current books, articles, and media on issues and skills in parent involvement.

To effectively deliver these services to such a large parent and teacher population, the Center has adopted a model of consultation, leadership training, and support to school-based personnel through the provision of a variety of indirect services.

As the parent involvement program has evolved over the past three years, a shift in emphasis has taken place to keep pace with the changing needs of the population. delivering inservice training to teachers and providing informational/educational seminars for district parents. These activities were designed to increase the awareness and skill levels of parents and teachers for communicating with one another through conferences, telephone calls, daily reporting systems, and other opportunities 
for interaction. Last year, for example, the Parent Center provided over 82 inservices for approximately 3,500 professionals across the system, on topics such as skills for parent-teacher conferences, stresses of parents of handicapped children, and general strategies for involving parents.

As the skill levels of teachers and parents have increased, the Center has shifted its primary emphasis for the current year to the development of parent-use materials (Figure 1 is an example) while continuing to offer workshops that address skill maintenance. The materials are developed at the Center and disseminated to school principals, counselors, and special education teachers for use with their own parent populations. This model of indirect service complements the consultant delivery system and further supports the Center staff's beliefs that their job is to help school personnel improve and enhance their own positive relationships with parents rather than having the Parent Center intervene directly in those relationships. The thrust of the Center then, is to train, support, and assist in the maintenance of the direct relationships teachers and parents develop as part of the education of each child.

To reach some of those "hard-to-reach" parents, Parent Center personnel have begun a new series of workshops on how to negotiate the school system, how to help a child build good study habits, and other topics of interest to parents. The workshops are held on-site in local industries such as Digital Equipment Corporation. In addition, staff members are appearing on television and radio interview programs to explain conferencing tips to parents, and the local cable television station is providing air time to run 30 -minute informational programs developed by Center staff on topics including living with an adolescent and positive ways to discipline children. We hope that arrangements can be made soon for parents to call in their questions to the presenters on these television segments. Also, radio stations are furnishing public service "spots" on tips for parents provided by the Parent Center. For a large urban district with a wide variety of parent needs and strengths, this is a parent involvement program that works!

\section{"BIRTH" OF A PARENT CENTER}

Parent centers necessarily must differ in their composition and activities. Some may be information centers, while others will have strong therapeutic orientations. Some may focus their activities on direct services to parents; others may address their attention to service providers. These were just a few of the considerations in developing the Parent Center in Albuquerque first as a demonstration project and later as a component of the Special Education Department of the Albuquerque Public School System.

\section{Assumptions}

One may make certain assumptions about the overall concept of parent involvement that affect the design and subsequent operation of a parent center. These assumptions may seem obvious, but in reality they often go unrecognized.

\section{Money}

Money will always be lacking to do all of the things that can be conceived in the name of parent involvement. For instance, the cost of running therapeutic parent groups may quickly use up a center's resources and touch only a small percentage of the parent population. The question of getting the most mileage for the dollar is a recurring one. Projects that spend thousands of dollars on a few parents are usually viewed as places to cut in times of scarce funds. Recognition of the "never enough money" does not automatically eliminate therapeutic services as a potentially valuable component, but it should help the developers put services like this in perspective.

\section{Time}

Even with unlimited financial resources, one may assume that time to accomplish all identifiable services will never be enough. Information may be out-of-date before it can be disseminated. The length of time to accomplish some therapeutic interventions may be prohibitive for small staff. Parents may lack the time and energy to attend meetings and educational workshops. How to use staff and parent time in the most productive ways is a constant concern, since there will never be enough time.

\section{Personnel}

Teacher training programs across the country have been slow in providing teachers with minimal skills in parent-teacher interaction strategies. Therefore, one can assume that the numbers of trained personnel to carry out all the desirable parent involvement activities will not be sufficient. Thus, the lack of available trained personnel will have an effect on the types of activities and programs designed. 


\section{"STREET-PROOFING" YOUR CHILD}

1. Teach your child what a stranger is. Most children view a stranger as someone who acts strange.

2. Teach your child not to take rides, candy, money or bribes from a stranger. Often children are "bribed" into being helpful or accepting help. A lost dog, kitten, or toy may be used as bait.

3. Teach your child never to accept an alternative way home. Children need to know that any change in plans will be relayed to them only through school personnel.

4. Teach your child that he/she has a private space that has to be respected by strangers.

5. Teach your child that any area covered by a bathing suit or underwear should not be touched by strangers.

6. Don't allow children to break the rules in your presence. Do not allow strangers to give them candy, ruffle their hair, etc. even when you are with them.

7. Provide "safe olaces" for your children on their way home. Show them places they can go if they need help, such as a neighbor's home, or a certain store to use the telephone.

8. Teach your child things to do if approached by a stranger such as: ignoring, walking away, using the safe places you have shown him/her in the neighborhood or, if approached by someone in a car, heading in the opposite direction.

9. Encourage your child to tell you if he/she has encountered a situation that makes him/her uncomfortable.

10. Practice and repetition of these tips will form good safety habits for your child. Review them and roleplay possible situations at regular intervals.

Adapted from remarks by Dr. Marian Shelton

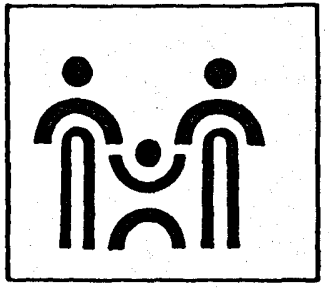

Distributed by: The Parent Center 1982

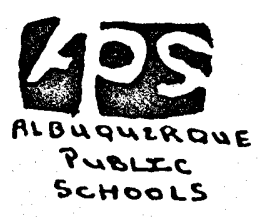

FIGURE 1

"Street-Proofing" Your Child 
The question arises as to how to get the most mileage out of the personnel's skills. One obvious answer is to have the personnel become trainers of trainers, thus using a multiplying effect. This has been proposed by some who recognize the futility of trying to provide direct mental health and information services to all who need them in our society (Guerney, 1969).

\section{Heterogeneity of Parents}

Although we recognize that parents of exceptional children comprise a heterogeneous group, this seems to be one of the most commonly violated conceptions. For example, experience has shown that not all parents are able to attend meetings or participate in school conferences even though they may be interested, committed parents. Sometimes life circumstances prevent their involvement. In these cases, our Parent Center encourages schools to send home a wide variety of information via newsletters, handbooks, personal notes, and educational fliers. In addition to this type of material, schools send home all kinds of permission forms for parents to sign.

In being responsive to the heterogeneity of parents, consideration must be given to the reading skills and levels necessary for understanding this material. The advent of microcomputer software programs to assess the readability of materials allows analysis of the various consent forms, rights explanations, and informational materials disseminated by school systems, parent coalition groups, and parent advocacy groups. Most of these materials appear to be written at high school and college levels. If the majority of materials is written at a level too difficult for a significant percentage of parents, "informed" consent and involvement cannot be easily attained. As a concession to Spanish-speaking people, institutions often present materials in Spanish. Unfortunately, many of the persons who cannot read the material in English cannot read it in Spanish either particularly at the reading level used.

Some parents are rich, and some are poor. Some have many children, and others have only one child. Parents who have a number of children may not be able to spend even a half-hour a day with just one of their children in a treatment program. Some children live with single parents, some with grandparents, some with both original parents, and some with no parents. In Albuquerque, for instance, approximately $50 \%$ of the children who were placed in classes for the behaviorally disordered were found to live with a single parent; the same was not true for other exceptionalities. For most children it is significant that both parents are working; for others it is significant that neither parent is working. Professionals often schedule meetings as if parents were available during the 9:00-3:30 school day. In a tight economy many parents are reluctant to take time off work.

Persons who express a concern for the individual differences among children curiously seem to operate differently far too often with regard to parents (and one can probably safely assume that the parent population is more heterogeneous than the children in a particular special education program). Parent involvement programs best serve the community when the design reflects the differences found among parents.

\section{Needs/Strengths}

While we can assume that parents of exceptional children are a heterogeneous group, we can also assume that all parents have a variety of needs and a variety of strengths. All parents have a need to be informed of their rights, for instance, and by law they are supposed to give "informed consent" to test and place their children. In practice, this does not happen (Dominguez, 1982), so a communication gap exists between parents and professionals (Korsch \& Negrete, 1972).

On the other hand, all parents have strengths. They know things about their children, and they feel things. This aspect of parenting often is not acknowledged unless a parent takes a forceful position.

A number of explicit or implicit assumptions, then, affect the development of parent centers. The following list is certainly not exhaustive, but by bringing these assumptions to an awareness level, priority activities for a parent center may be better defined:

1. Money will always be lacking to do everything a center may want to do.

2. Time will always be lacking to accomplish all of the goals or to fulfill all of the parent needs.

3. Well qualified, experienced personnel will always be lacking to perform all of the individual services needed. A corollary to this assumption is that most university training programs will not provide enough specialized training in this area.

4. Parents of exceptional children are not a homogeneous group.

5. All parents of exceptional children have strengths, and all have needs to be met.

\section{The Mirror Model of Parental Involvement}

Consideration and reflection of these assumptions led to development of a comprehensive model for parent involvement in Albuquerque. The model was conceived 
in order to put into perspective the various types of activities that might take place in a parent involvement center.

The Mirror Model of Parental Involvement (Figure 2) reflects some of the assumptions just discussed. The top half of the model addresses the needs that parents of exceptional children have, and the bottom half addresses the strengths that parents have. By showing various levels, some of the individual differences are reflected. The model differentiates between things all parents need and activities from which only a few will benefit. Design of the parent program should reflect time and commitment directed toward the all and most levels, with selected involvement at the few and some levels. The payoff in numbers served and visibility of the Albuquerque Center is found at the former two levels.

Our Parent Center staff did not expect that any one unit in any school system would have all of the levels operating at any given time, but the model did provide a framework for helping staff assess the different types of activities that were going on (the real) so that this could be compared with what the center would like to be doing (the ideal). Within a school system the size of Albuquerque's, evidence could be found of all levels of activity operating successfully.

The various levels will be discussed in some detail to show how they influenced the activities proposed for our Parent Involvement Center. In many ways, the decisions

WHAT HOW

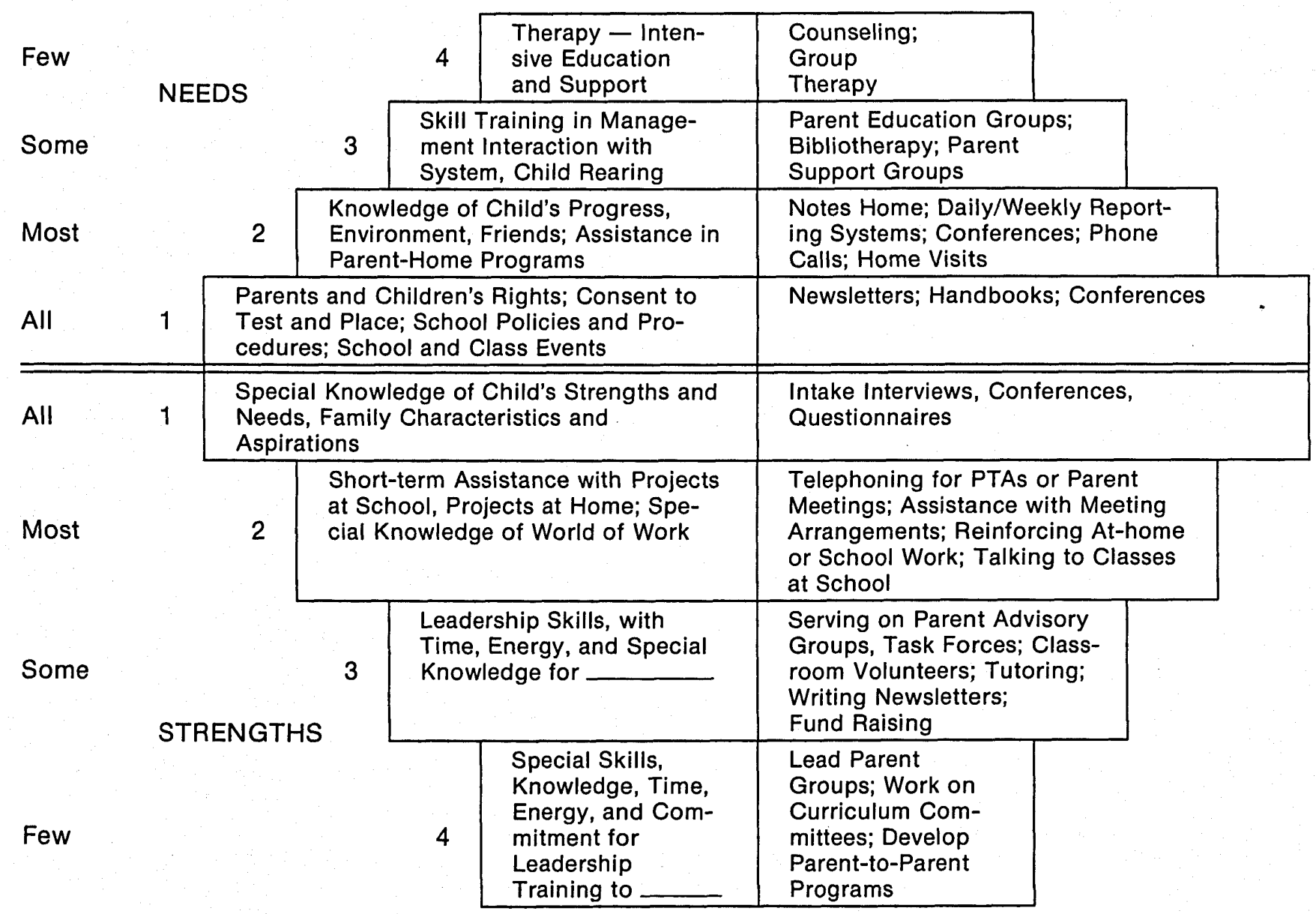

Developed by the Parent Center, Albuquerque Public Schools, 1982

FIGURE 2

Mirror Model of Parental Involvement 
were influenced by the assumptions drawn about parent involvement and by the Mirror Model.

\section{Needs}

Level 4 Needs. The staff's experience indicated that only a few parents were in dire need of therapeutic services. In-depth counseling is extremely expensive and time consuming. In a school system of approximately 11,000 special education children, probably no more than $5 \%$ of the parents would require this level of treatment - but that might mean 500 families. The three- or four-member staff could find its time almost totally consumed by this group of parents. Although the staff had the proper training to provide some treatment at this level, it would be a questionable use of a large percentage of the staff's time. Some counseling was and is provided, but the time was put to better use by developing a sourcebook of community referral agencies. This handbook, containing the most commonly used or needed community services for families; is disseminated to each school and is updated periodically.

A second service that only a few parents need each year, but which they request and find useful, is a relocation service. If a family is moving from Albuquerque to another community, one of the staff members calls ahead to get some information as to programs available, materials needed in the transfer, and the name and number of a contact person. This service is not necessarily therapeutic, but it is used by only a few parents a year. In Albuquerque, severely and profoundly handicapped children are located in integrated schools and classrooms. Parents are surprised that this is not true across the nation. Therefore, the relocation service has been useful regarding questions and answers about prospective programs.

By design, Level 4 Need activities are not allocated disproportionate amounts of money, time, or personnel.

Level 3 Needs. Some parents have a need to develop some skills. This need may represent only $20 \%$ of the families at any given time, but teaching parents skills is time-consuming. Many programs have been developed to help parents with their listening skills, assertiveness, management skills, coping skills, and knowledge acquisition. Most of these programs involve one or two leaders and a small group of parents ( 10 or fewer) meeting for a number of sessions.

A number of the programs are well-defined, with leader's guides, tapes, workbooks, posters, and step-bystep instructions. Although qualified leaders often modify the programs to suit participants' needs, the programs are organized so that many people can learn to use them. Some of the programs (in kit form) used by the Parent Center are:

\section{Systematic Training for Effective Parenting}

(STEP), 1976

Authors: Dinkmeyer \& McKay

Source: American Guidance Service, Inc. Circle Pines, MN 55614

The Art of Parenting, 1977

Authors: Wagonseller, Burnett, Salzberg, \& Burnett

Source: Research Press

2612 N. Mattis Ave.

Champaign, IL 61820

Managing Behavior

Author: McDowell

Source: Research Press

2612 N. Mattis Ave.

Champaign, IL 61820

Teaching Involved Parenting (TIP), 1982

Authors: Wagonseller \& McDowell

Source: Research Press

2612 N. Mattis Ave.

Champaign, IL 61820

Other well-defined programs that are not in kit form, such as Gordon's Parent Effectiveness Training (1970), have been attractive to participants.

Staff members, with teachers and other educators, designed a variety of programs to be tried with families of exceptional children. At one time or another over the past 56 years, programs have been implemented to:

- teach parents to test their own children.

- teach parents to write their own IEPs.

- teach parents to make nutritional snacks.

- teach parents to make the transition between preschool and elementary; elementary and midschool; and mid-school and high school.

- teach parents to be active participants in conferences.

- teach parents their rights, etc.

- teach parents about specific handicapping conditions.

- teach parents about sex education.

- teach parents how to work with siblings.

- teach parents listening, communication, and awareness skills.

Most of the parent group activities grew out of needs identified by teachers or by a small group of parents in search of a group. The strategy largely agreed upon by staff members was to demonstrate a particular program, develop a new program, or co-train with someone who could continue the program. Direct service by staff was 
considered too time-consuming unless demonstration, development, or training was involved. This was a difficult decision because most qualified staff members enjoyed the work done at levels 3 and 4.

Parent group work involving skill building is quite popular in the literature (Cooper \& Edge, 1978; Rutherford \& Edgar, 1979; Kroth \& Scholl, 1978). Although it is certainly needed and desirable, group work has to be put into perspective when money, time, and personnel are limited.

Level 2 Needs. Most parents of exceptional children have a need to know. They want conferences with teachers, coordinators, diagnosticians, doctors, therapists, and any of the significant others in the child's life. Level 2 activities encompass many information-sharing interactions.

Since a number of parents engage in "doctor shopping" because of their need to know, this may be interpreted as a need to cover some of the material over and over. Certain authors refer to this phenomenon as a "denial stage"; however, professionals simply may not have learned to communicate well with parents. For example, Dembinski and Mauser $(1977,1978)$ found, in companion studies with parents of learning disabled children and gifted children, that parents were quite concerned about professionals' use of jargon. Korsch, in

\section{PRE-CONFERENCE}

1. Notify

- purpose, place, time, length of time allotted

2. Prepare

- review child's folder

- gather examples of work

- prepare materials

3. Plan Agenda

4. Arrange Environment

- comfortable seating

- eliminate distractions

\section{CONFERENCE}

1. Welcome

- establish rapport

2. State

- purpose
- time limitations
- note taking
- options for follow-up a series of studies that looked at the communication gap between doctors and patients, found jargon to be one of the continual obstacles in the path of understanding (Korsch \& Negrete, 1972).

Barnlund (1976) has been interested in the ineffectiveness of the communication process. Some of the obstacles that Barnlund identified were: ego involvement differences in knowledge social status communication purposes emotional distance one-way communication verbal manipulation ambiguity of language role of jargon pressures of time.
Little has been done in special education to study this phenomenon. Williams (1983), however, found that even when she spent considerable time (one-two hours) interpreting test information to parents, a significant lack of agreement still existed in parents' interpretation of what was said.

Since most parents were involved in this level of participation, Center staff surmised that time should be spent in improving this type of communication. Guides were made available to parents and teachers. The Conference Checklist (Figure 3) was provided to teachers in inservice training workshops or as a handout when staff

\section{CONFERENCE (continued)}

3. Encourage

- information sharing

- comments

- questions

4. Listen

- pause once in awhile!

- look for verbal and nonverbal cues

- questions

5. Summarize

6. End on a positive note

\section{POST-CONFERENCE}

1. Review conference with child, if appropriate

2. Share information with other school personnel, if needed

3. Mark calendar for planned follow-up 


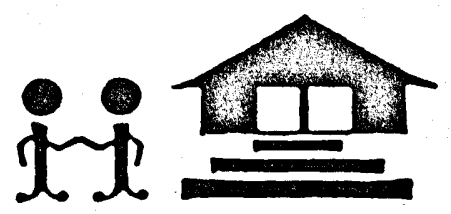

A parent-teacher conference is a chance for two very important adults to talk about how a child is doing in school. It is a time for you, as a parent, to ask questions about any concerns you may have about your child's progress. Since the time allowed for conferences is often limited, it is helpful for both parents and teachers to plan ahead.

Here is a checklist that may help you get ready for your conference.

HOW TO GET READY

1. Make a list of questions and concerns.

2. Ask your child if he/she has questions for the teacher.

3. Arrange for a babysitter for small children.

\section{QUESTIONS YOU MAY WANT TO ASK}

1. In which subjects does my child do well? Is my child having any trouble?

2. Does my child get along with other children?

3. Does my child obey the teacher?

4. How can I help at home?

\section{QUESTIONS THE TEACHER MAY ASK YOU}

1. What does your child like best about school?

2. What does your child do after school?

(What are his/her interests?)

3. Does your child have time and space set aside for homework?

4. How is your child's health?
QUESTIONS THE TEACHER MAY ASK YOU (continued)

5. Are there any problems that may affect your child's learning?

6. What type of discipline works well at home?

\section{AT THE CONFERENCE}

1. Please arrive on time.

2. Discuss your questions and concerns. (Use your checklist.)

3. Share information that will help the teacher know your child better.

4. Take notes if you wish.

\section{AFTER THE CONFERENCE}

1. If you have more questions, or you ran out of time, make another appointment.

2. Tell your child about the conference.

3. Plan to keep in touch with the teacher.

4. If you were satisfied with the conference, write a note to the teacher.

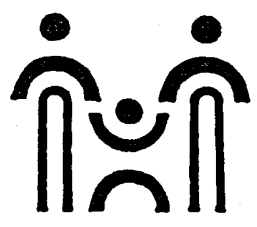

FIGURE 4

Parent Tips for School Conferences

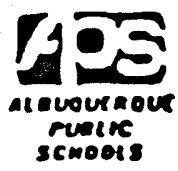

members were on site visits. A copy of Parent Tips for School Conferences (Figure 4) was sent to each school to make copies to send home to all parents. The checklist for parents evolved from one that was originally developed and found to have an 11.6 grade readability level. The suggestions were eventually rewritten at about a 6 th grade level - about the same level as an Ann Landers column.

The staff also presented On Being An Active Participant (Kroth, 1979) at parent meetings. This is basic information that parents find useful in preparing for, and participating in, IEP conferences or appraisal and review meetings. The staff also made available to parents cards that provided them with tips for conferences (Figure 5).

Numerous materials have been developed to provide parents and teachers with information. Some of the handouts are on building study habits and self-esteem, and on reducing stress; these provide basic tips for dealing with children. In addition, the library at the Parent Center is available to teachers and parents almost 12 months a year from 8:00 a.m.-4:30 p.m. and sometimes during the evening. The staff generally agreed that simply having information can be therapeutic.

Various general interest presentations have been made available to parents. With 11,000 parents of exceptional 


\section{CONFERENCE TIPS}

1. Initiate conferences any time.

2. Write down questions and suggestions beforehand.

3. Take a friend if you want.

4. If there are a number of people, sit in the middle not at the end or facing them.

5. Take notes.

6. Ask for clarification (do not accept jargon).

7. Ask to see any records that you want.

8. Ask for copies of any records that you want (you may have to pay).

9. Sign only papers that you understand.

10. Be supportive and positive.

\section{PARENT INVOLVEMENT CENTER}

1700 Pennsylvania N.E.

Albuquerque, NM 87110 UNM/APS

PHONE

NAME

FIGURE 5

Tips for Parent Conferences

children plus other interested parents as a potential audience, the programs are well attended. Topics have included:

Divorce and Separation: Effects on the Family

Assertive Discipline

Surviving Adolescence: Tips for Parents

Sex Education: Issues and Concerns

Drugs and Alcohol: What Parents Should Know

Stress Management for Parents

A number of authors have been concerned with this level of interaction (Kroth, 1975; Kroth \& Simpson, 1977; Seligman, 1979; Simpson, 1982). Parents view teachers as a primary source of information and support. Therefore, a major emphasis of the Parent Center has been to provide teachers with knowledge and skills for communicating effectively with parents. This includes not only conferencing skills, but daily report card systems, telephone calls, handbooks and newsletters, as well.

Level 1 Needs. All parents need to be apprised of their rights and the rights of their children. Procedural safeguards have been established to protect children who have been identified as exceptional from being denied placement or being placed without proper evaluation.
Even though school personnel have documents with parent signatures, the parents are often not aware of what they have signed (Dominguez, 1982). Even when diagnosticians are careful to explain their findings, parents commonly fail to recall what was presented (Williams, 1982). As discussed earlier, the readability of materials provided to parents is often at a high school or college level. These materials, even though they may have been provided in "good faith" by school districts, are often not appropriate for all parents. The Parent Center staff has become sensitive to this problem during the past few years and is taking steps to alleviate it.

Filmstrip programs can be used to help explain procedures to parents. The following ones are available at the Parent Center for use by school personnel:

\section{Implementing Procedural Safeguards $-A$ Guide for Schools and Parents \\ Author: Council for Exceptional Children (CEC) \\ Source: CEC with the Children's Television Workshop \\ 1920 Association Dr. Reston, VA 22091 \\ PL 94-142: Putting Good Intentions to Work - A Program for Parents and Teachers, 1981 \\ Authors: Ruegamer, Wagonseller, and Kroth \\ Source: Research Press \\ 2612 N. Mattis Ave. \\ Champaign, IL 61820}

Since this is an area of the Mirror Model that addresses all parents, the staff has tried to use a fair proportion of time and energy to improve communications. It is also an area that should be reemphasized from time to time for maintenance of activity level and skill development.

\section{Strengths}

Level 1 Strengths. All parents know things about their children and their families that professionals need to know in order to provide the best service for children. As mentioned earlier in the citation of Hobbs's (1978) statement describing parents as the true experts on their children, the underlying philosophy of the Parent Center has been to help parents become case managers for their own children.

Parents are sometimes overwhelmed by professionals. Parents who have exceptional children may be receiving service and advice from five to 20 outsiders. One father, for instance, reported that his child was being seen by six physicians, as well as other therapists. Therefore, even well-meaning professionals with exemplary programs 
may produce negative effects on families (Doernberg, 1978).

Capitalizing on the strengths that all parents have is a matter of training for both parents and professionals. Sensitive professionals with good listening skills can take advantage of the specialized knowledge that parents possess, and parents who become aware of the importance of their role in case management can become more productive.

Level 2 Strengths. Most parents of exceptional children have the time, strength, and energy to provide some help at home or at school. They may become part of a telephone tree or serve as a room parent. They may provide cookies or other snacks for a parent meeting, or furnish reinforcers for a home/school program.

Professionals should be reminded not to take advantage of the parents who are willing to volunteer for limited service. Parents, like teachers, can become "burned out." The only difference is that parents cannot quit like teachers can, nor can they have the summer off.

Level 3 Strengths. Some parents have the time and knowledge to support professionals with advice, counsel other parents, provide specialized help, or teach children. Many parents in Albuquerque have contributed their services in the classroom. They have learned to use "canned" programs like Distar or Monterey. Parents sometimes help develop newsletters and handbooks for use with other parents.

One of the potential problems is that many professionals have not been trained to use volunteers. As the problem was identified at the Parent Center, the staff developed some handouts offering suggestions to teachers, in addition to collecting materials from other centers and using them in conjunction with workshops for teachers. Center staff also provided assistance in networking interested school personnel with several parents in the community who are "professionals" at setting up parent volunteer programs.

Other materials that should be developed or collected include information on how to be effective advisory board or task force members. Unfortunately, parents are sometimes asked to act in capacities for which they have not been trained or provided with guidelines (Kroth \& Scholl, 1978). This can lead to unhappiness on the part of both parents and professionals.

Parents can be a rich source of information and service if professionals are taught to take advantage of parent skills. This is often a neglected area.

Level 4 Strengths. Parents have long been regarded as major sources of strength and support for other parents. Large communities have traditional parent organizations such as the Association for Children with Learning Disabilities, Association for Retarded Citizens, and
Association for Gifted and Talented Students. Other support groups include Tough Love, Parents Anonymous, and Recovery, which may be useful to some parents.

Parents Reaching Out (PRO) is a support group of parents for parents in Albuquerque. It is similar in purpose to Pilot Parents, or parent-to-parent programs. Parents in this group are available when other parents need them, when children are going through operations, and as advocates. They also are part of the Parent Support Network that functions throughout New Mexico. During the past four or five years, staff members at the Parent Center have assisted in providing training for these parents. Probably the most important function, however, has been that of providing a network for parents.

The Mirror Model was the conceptual framework that formed the basis for the model demonstration program that was federally funded at the Center. In our experience, the Mirror Model is the foundation of a parent involvement program that works. The following section describes the "train the trainers" delivery system designed for a grant funded by the Division of Personnel Preparation.

\section{“TRAIN THE TRAINERS" MODEL}

Public Law 94-142 brought with it a requirement that parents and teachers work together in the development of educational plans for children. Also, professionals have fairly well accepted the premise that the family environment has a strong and, in many cases, major influence on children's educational growth and development (Coleman, 1966; Jencks, 1972). Most elementary school districts in the United States require parentteacher conferences (Kroth \& Simpson, 1977). With this as background information, the obvious question is: Why do teacher training personnel ignore this component in the training program?

Most special education teachers know how to formulate an individualized education program for children and have the strategies to implement that program. They know how to write behavioral objectives, and they are able to measure the effectiveness of their treatment. For six hours a day, five days a week, they demonstrate the ability to manage the learning environment and the behavior of the exceptional children in their charge. They are expert in all aspects of direct child instruction. But an essential component to the facilitation of child growth is missing in their repertoire of skills. As a result of its absence in their training, teachers often lack 
expertise in the important area of parent-teacher communication and interaction (Kroth, Otteni, \& Parks, 1982).

Parent conferencing coursework has been offered at the University of New Mexico consistently through the 1970 s and into the 1980s. Hundreds of teachers have taken the course to learn some rather basic skills in communicating with parents. Development of the course was prior to the federal mandates and, as a result, much of the early content centered on skills in listening, communicating via newsletters, handbooks, daily reporting systems, and making referrals to community agencies. Through the coursework, teachers have become aware that parent agencies such as the Albuquerque Association for Children with Learning Disabilities and the Association for Retarded Citizens can provide assistance and support to parents. The major emphasis of the course has been to facilitate the growth of children through cooperative relationships between parents and teachers. The coursework is largely concentrated upon levels 1 and 2 of the Mirror Model. This is where most parents are affected.

The one group of professionals with whom parents have sustained contact over time is classroom teachers. According to a literature review by Seligman (1979), parents view teachers in a positive light, for the most part:

Although parents have made complaints about and widely hold negative attitudes toward professionals in general, teachers tend to be spared ... On the whole, parents tend to value their child's teacher as one who is generally knowledgeable, a specialist in working with children and a source of encouragement and support. (pp. 31-32)

In light of the above, the fact that all teachers in training do not have the opportunity to have coursework and experience in the important area of interacting with parents is unfortunate.

\section{Developing a Model Program}

Training initially focused on local teachers through university coursework and school- or center-based inservice sessions. Also, teachers around the state and across the country were involved through presentations and consulting within individual school systems and at the national conferences of a variety of professional organizations. As the volume of requests for services grew and satisfied consumers visited the Center and asked for assistance in presenting the information to colleagues, the need for another approach with a wider scope to effectively multiply the effects of training became apparent.
At the same time, a need had been identified for the content of the parent counseling course to be offered to teachers and other professionals outside the Albuquerque area. To facilitate the delivery of this type of course in rural areas, lecture notes, handouts, media, and instructions for delivery were packaged into what was fondly referred to as the "course in a box." The format and design of the "course in a box" allowed for easy transport and minimal preparation for an instructor to teach the two-credit-hour course in a rural area without many resources.

Tying the perceived need for a new strategy of delivery of services for a greater number of professionals to development of a comprehensive training package in the area of parent involvement, the idea for a unique delivery approach was conceived. If a project staff of three, with limited doctoral student support, could not satisfy the needs for direct training for teachers, why not target a group who could? Therefore, the concept of "training the trainers" evolved. By narrowing the focus to impact the individuals from across the country who are responsible for training and retraining teachers, the effects certainly could be multiplied much more rapidly. Federal funding from the Department of Personnel Preparation provided the resources to implement a plan that would hold several Institutes for Parent Involvement. At these Institutes, teacher trainers active in parent involvement would receive intensive instruction, along with practice using developed materials, for offering a two-credit-hour course entitled "Strategies for Effective Parent-Teacher Interaction."

Six individuals were selected as a working advisory board on the basis of the following criteria: (1) demonstrated leadership and experience in university training programs for teachers in parent involvement; (2) publications in the area of parent-teacher interaction; (3) participation in an informal seminar on parent education held in Albuquerque in August of 1979; and (4) service as members of a network core of parent involvement trainers. The following professionals served as advisors and trainers for the Institute's "Strategies for Effective Parent-Teacher Interaction" module: Dr. Ray Dembinski, Northern Illinois State University; Dr. Denzil Edge, University of Louisville; Dr. Kay Hartwell, Arizona State University; Dr. Jennifer Olson, University of Idaho; Dr. Richard Simpson, University of Kansas; Dr. Bill Wagonseller, University of Nevada at Las Vegas. During the history of the training project, which is still ongoing, the trainers provided assistance in consultation for development of materials, plans for the Institute, and recruitment of participants.

Thirty-eight trainers representing 17 states from Maine to Florida to California participated in the first two 
Institute sessions. Their documented work responsibilities reflected university, public school, state-supported school, and related agency training positions. Their targeted training populations were split among teachers, parents, and university students in education.

\section{Initial Effects}

During the period June-December, 1980, 31 individuals demonstrated their commitment to parent involvement and the relevance of Institute materials by offering 21 inservice workshops and scheduling one Institute in Orlando, Florida, for 90 professionals. Also, the initiation of three two-credit-hour extension courses utilizing the specific "Strategies for Effective Parent-Teacher Interaction" course design and materials, to be offered in Belen, New Mexico, Zuni, New Mexico, and Roughrock, Arizona, as well as the delivery of one one-credit-hour course in Montgomery, Alabama, is regarded as significant activity.

The thrust of the project's training effort, therefore, was directed to the training of trainers. Besides continuing to provide formal and informal preparation for regular and special education teachers in the immediate geographic area, the effects of training were multiplied by delivering training and materials to trainers from across the nation. These trainers were then able to return to their home settings and impact their own locales. One of the unique aspects of this training model was that not only are trainers trained to deliver services to teachers and parents, but master trainers are trained to also present and replicate Institutes across the country, thereby involving increasing numbers of teacher trainers. A prime example of this multiplying effect is Project Enrich in Kentucky. Dr. Edge and staff from the State Department of Special Education combined to train hundreds of trainers with the "Strategies for Effective Parent-Teacher Interaction" materials; these individuals, in turn, returned to their communities to train classroom teachers. The potential effect of such efforts is mindboggling.

\section{Institute Design}

The Institute design provides for a high level of interaction between participants themselves, participants and trainers, and the entire group in general. For Institute purposes, the ratio of participants to each master trainer is limited, to ensure quality and quantity of contact time. Based on previous experience, one master trainer for 10 or fewer participants appears to allow the high degree of individual and group interaction critical to this type of training model.

Program content of the Institute for Parent Involvement, entitled "Strategies for Effective Parent-Teacher Interaction," is designed for delivery as a two-credithour course or nine three-hour inservice sessions. The course format consists of lectures, demonstrations, small-group activities, projects, media, and discussion to increase positive parent-teacher involvement and communication. An extensive, bound Leader's Guide, audiotapes, transparencies, and textbook are included as part of the Institute training. The Leader's Guide provides a comprehensive description of the Institute training program, as well as detailed instructions for delivery. Each unit is designed so that it can be presented as a part of an entire course or as an inservice workshop.

\section{Course Content}

To refrain from getting enthusiastic about the "parents are teachers" philosophy is difficult. Stevens (1982) has pointed out that most of the parent training programs center on teaching parents to accomplish educational or behavioral goals for their children. Little has been written about helping teachers and parents exchange basic information. From their research, Dembinski and Mauser (1977, 1978) concluded that parents of gifted and learning disabled children want information on how their children are doing in school - and they want it without the jargon. Many teachers have discovered the usefulness of phone calls and notes home in keeping parents informed. Thus, the emphasis of course content is in those areas of basic communication. Little is done with parent education groups, as was explained in the rationale for the Mirror Model.

Essentially, the content was designed around the premise that most teachers are expected to perform and have the knowledge and skills needed to effectively perform these functions. The major topics are:

1. Values System. Often, teachers individualize for children but do not individualize for parents. Recognition that parents have a variety of value systems, economic backgrounds, educational levels, and social expectations can sometimes facilitate communication between school and home. Activities and interviews help teachers recognize differences in point of view.

2. Family Dynamics. Most teachers need to become more aware of what having a handicapped child in the home is like. Some literature is available for 
teachers to read, but face-to-face experiences are additionally helpful. Interviewing parents and providing parent panels are useful. Camp experience with parents and exceptional children gives increased insight.

3. Communication Techniques. Since parents cannot always attend conferences or visit school, other techniques may be pursued. Parents appreciate receiving newsletters and handbooks. They need frequent information, so daily reporting systems, notes, daily notebook exchanges, scrapbooks, home visit techniques, and the telephone come into play. With microcomputer printouts, telephone conferencing may take on increased importance.

4. Informational Needs of Parent. Most parents would like more information on what they can do at home with their children, what would make appropriate gifts, what summer programs are available, information about community services, field trips for children, books to read, and so on.

5. Conferencing Skills. These include listening skills, as well as techniques for presenting progress to parents. Since all teachers hold conferences, a fair amount of time is devoted to this subject. Arranging the environment, opening and closing a conference, dealing with emotions, and the like are topical areas.

6. Difficult Conferences. Some time is spent on unusual or difficult conferences in which teachers may find themselves involved. Tips on how to deal with aggression and anger and discussion on delivering sensitive information or "bad news" are presented.

7. Legal Information. The whole issue of informed consent seems to be cloudy for most educators. Program changes are made without informing parents. IEPs are written prior to conferences, and parents are merely asked to sign. Due process procedures are not explained to parents. Parents often do not know what the categorical classifications of their children are, what types of programs they are in, or what kind of services they are entitled to have. Strategies for encouraging higher levels of informed involvement are highlighted.

Over the past three or four years, many trainers have participated in Institute activities. To perpetuate the original mission of providing the "course in a box" to trainers after federal funds ceased, the project was put on a paying basis. Participants are charged a fee for materials and training. As a result, Institutes for Parent Involvement have been conducted and are continuing to be conducted across the country without federal support.

\section{What Next?}

Undoubtedly the program will continue. From the beginning, its developers have felt a sense of mission. Of course, continued modification and adaptation will be needed for various populations.

In the summer of 1981 , a course using the materials was presented on the Gallaudet College campus, for parent liaison workers in state schools for the deaf around the country. The course received special recognition from the North American Association of Summer Sessions. Because of the work of Gallaudet College personnel in various countries, some of the materials have been translated into Spanish for use in Latin American countries.

In New Mexico, a Parent Support Network project, funded by the Developmental Disabilities Planning Council, was developed. Teams of professionals and parents were formed throughout the state, and training was provided for them. Some of the material from the "Strategies for Effective Parent-Teacher Interaction" course was used in this effort.

In the summer of 1982, workshops for Native Americans from three pueblos were conducted by Pat Putnam and coordinated by the Southern Pueblo Agency. Some of the original materials were used, and other materials are being developed or adapted to meet the unique needs of diverse cultures. Work is also being done with members of the Navajo Nation.

The interest of people around the country in improving the working relationship between parents and teachers is unquestioned. The goal of the developers and implementers of the "Strategies for Effective ParentTeacher Interaction" has been to facilitate this relationship. This is another parent involvement program that works.

\section{KEYS TO BUILDING A SUCCESSFUL PARENT INVOLVEMENT PROGRAM/CENTER}

We receive many requests from parents and professionals across the country for tips on developing parent involvement programs tailored to an individual community's needs. From our experience, a number of "keys" to successful implementation of a program are:

1. School board and administrative commitment.

a. Educate, inform, and "sell" your board members and top administrators on the benefits of a program of planned positive parent involvement. 
b. Identify key individuals who are "ripe" to support you.

c. Do your homework - be knowledgeable about other programs - the research, cost factors, etc.

d. Involve active, articulate parents in your efforts.

2. Selection of an individual or team to coordinate development of the program/center.

a. Select individuals who have established credibility with community and district professionals and parents.

3. Community interface.

a. Conduct a needs/strengths assessment of parents.

b. Tailor program design to community characteristics (e.g., single parents, working parents).

c. Solicit and utilize input from existing community agencies.

d. Establish a community network to support goals of the program; coopt and strengthen existing services.

4. Advisory/planning committee.

a. Assist in translation of needs/strengths survey to program design.

b. Include representation from parent organizations, individual parents, school administrators and teachers, university faculty, city government, etc.

c. Recognize the importance of a variety of groups' feeling a sense of ownership.

d. Develop program plan with goals, objectives, timelines, location, fiscal implications, etc.

5. Presentation of plan to district decision makers.
a. Emphasize integration of the plan into the total school program.
b. Stress cost effectiveness of establishing a pre- vention-oriented education program for parents and teachers.
c. Acknowledge and support existing parent in- volvement programs.

6. Identification of personnel and site.

a. Select individuals with established credibility with community and district parents and professionals. b. Choose a centrally located site, preferably away from the central administration.

c. Take care to establish a supportive relationship with any other personnel at the site who may feel displaced or threatened by the presence of a new program. Invest time in explaining the program and its goals to those at the new site. "Move in" slowly and cautiously.

7. Implementation/start-up phase.

a. Consider how to introduce to district personnel.

(1) Large meeting, small groups, individual contact?

(2) Address initial goals and objectives clearly, but retain ability to be flexible and modify program.

(3) Use examples in explaining program.

(4) Be short and to the point initially.

(5) Invite suggestions and involvement.

b. Secure a statement (verbal or written) of support and confidence from top administration, to be shared with district personnel.

c. Keep key individuals posted and involved.

d. Reinforce and acknowledge those who have rendered support in development.

e. Strive to assist and support other personnel in looking good. The role of a Parent Center is to help school personnel and parents develop cooperative relationships.

f. Plan a year for program development and staff training.

(1) Utilize a national network of trainers working with parent involvement programs.

(2) Focus on strategies for effecting the greatest impact with a small staff (e.g., a "train the trainers" model).

(3) Experiment, and don't be afraid to make mistakes.

(4) Seek continued counsel of advisory group.

8. Initiation of service delivery.

9. Evaluation and revision.

In addition, when planning a parent involvement program, be sure to consider:

1. Who can help?

a. University personnel.

(1) By providing credit hours for courses or inservices for teachers in strategies for working with parents. 
(2) By serving as catalysts with local school administrators.

(3) By generating seed money for pilot projects.

(4) By supplying space or materials.

b. Parent organizations such as ARC, ACLD.

(1) By keeping in touch with parent needs in the community.

(2) By marshalling positive, vocal support from parents for the venture.

(3) By providing complementary services for parents, such as advocacy (a districtsupported center cannot directly provide advocacy services and remain viable with the administration).

2. What services are already in place?

a. Community agencies.

b. Parent organizations.

c. Other school-based personnel.

d. Decide how to coopt and support these services while designing your program to provide a comprehensive approach that includes them.

3. How much education and persuasion will be needed?

a. Assess the awareness level of the school board and administration.

b. Assess the climate of parent-school relations. Is there a history of conflict or of cooperation?

4. How little/how much money do you need?

a. Develop alternate plans for personnel, site, materials.

Parent-teacher interaction is too important to be left to chance. Informed parents can support at home what is being taught at school. Also, in these times, when only $25 \%$ of the voting public has children in school, school professionals and parents must be united in their efforts to provide financial support to the schools.

The programs described above are parent education programs that work. Perhaps the best evaluation of their effectiveness is that they are still in existence after federal support monies have ceased. Of course, we recognize that the seeds were planted in rich soil and supported by caring professionals and parents in the Albuquerque community, the state of New Mexico, and across the nation.

\section{REFERENCES}

Barnlund, D. C. The mystification of meaning: Doctor-patient encounters. Journal of Medical Education, 1976, 51, 716-725.

Coleman, I. S. Equality of educational opportunities. Washington, DC: U.S. Government Printing Office, 1966.

Cooper, J. O., \& Edge, D. Parenting: Strategies and educational methods. Columbus, OH: Charles E. Merrill, 1978.

Dembinski, R. J., \& Mauser, A. J. Parents of the gifted: Perceptions of psychologists and teachers. Journal for the Education of the Gifted, 1978, l(2), 5-14.

Dembinski, R. J., \& Mausr, A. J. Parents of the gifted: Perceptions of psychologists and teachers. Journal for the Education of the Gifted, 1978, 1(2), 5-14.

Doernberg, N. J. Some negative effects on family integration of health and educational services for young handicapped children. Rehabilitation Literature, 1978, 39(4), 107-110.

Dominguez, J. C. The effects of training on special education teachers perceptions, knowledge and interactions with parents. Unpublished doctoral dissertation, University of New Mexico, 1982.

Gordon, T. Parent effectiveness training. New York: Peter H. Wyden, 1970.

Guerney, B. G. Psychotherapeutic agents: New roles for nonprofessionals, parents and teachers. New York: Holt, Rinehart \& Winston, 1969.

Hobbs, N. Classification options: A conversation with Nicholas Hobbs on exceptional child education. Exceptional Children, 1978, 44, 494-497.

Jencks, C. Inequality: A reassessment of the effect of family and schooling in America. New York: Basic Books, 1972.

Korsch, B. M., \& Negrete, V. F. Doctor-patient communication. Scientific American, 1972, 227, 66-74.

Kroth, R. L. Communicating with parents of exceptional children. Denver, CO: Love Publishing Co., 1975.

Kroth, R. L. Unsuccessful conferencing (or we've got to stop meeting like this). Counseling \& Human Development, 1979, 11(9), 1-11.

Kroth, R., Otteni, H., \& Parks, P. Parent involvement: A challenge for teacher training institutions. Building an Alliance for Children, 1982, pp. 181-205.

Kroth, R. L., \& Scholl, G. T. Getting schools involved with parents. Reston, VA: Council for Exceptional Children, 1978.

Kroth, R. L., \& Simpson, R. L. Parent conferences as a teaching strategy. Denver, CO: Love Publishing Co., 1977.

Rutherford, R. B., \& Edgar, E. Teachers and parents: $A$ guide to interaction and cooperation. Boston: Allyn \& Bacon, 1979.

Seligman, M. Strategies for helping parents of exceptional children. New York: Free Press, 1979.

Simpson, R. L. Conferencing parents of exceptional children. Rockville, MD: Aspen Systems Corp., 1982.

Stevens, M. V. The effects of training on parents' information level and behavioral characteristics in relation to special education school conferences. Unpublished doctoral dissertation, University of New Mexico, 1982.

Williams, B. Diagnostician-parent communication. Unpublished doctoral dissertation, University of New Mexico, 1983. 